\title{
Extent of anterior clinoidectomy for clipping of carotid-ophthalmic aneurysms predicted on three-dimensional computerised tomography angiography
}

\author{
Tomasz Szmuda ${ }^{1}$, Paweł Słoniewski ${ }^{1}$, Shan $\mathrm{Ali}^{2}$, Alexandra Kamieniecki ${ }^{2}$, Jarosław Dzierżanowski ${ }^{1}$ \\ ${ }^{1}$ Neurosurgery Department, Medical University of Gdansk, Gdansk, Poland \\ ${ }^{2}$ Student's Scientific Circle, Neurosurgery Department, Medical University of Gdansk, Gdansk, Poland
}

\begin{abstract}
Aim of study. We aimed to verify the value of computerised tomography angiography (CTA) on predicting the extent of anterior clinoidectomy that is optimal for particular carotid-ophthalmic aneurysms (COAs).

Clinical rationale for study. The anterior clinoid process (ACP) often impedes the complex microsurgery of COA. Complete removal of the ACP ensures safe clipping; however, it also may increase the risk of severe complications. The probability of performing a successful partial anterior clinoidectomy could be evaluated by preoperative CTA.

Materials and methods. 28 patients with either a ruptured $(n=4)$ or unruptured COA were included in this prospective, single-centre, observational study. One aneurysm was giant, two were large, and the rest were smaller. Successful aneurysm clipping was the aim in all cases. The anterior clinoidectomy was preoperatively planned on multiplanar three-dimensional reconstructions of CTA images (3D-CTA) which resembled the typical view of a frontotemporal craniotomy. Finally, the predicted clinoidectomy was compared to the extent of the actual clinoidectomy.

Results. 21 aneurysms (75\%) projected superolateral or superior. The ACP was completely and selectively resected in $25 \%$ (7 of 28 ) and $67.9 \%$ of patients (19 of 28 ) respectively. Optic nerve (ON) unroofing was always performed in the case of total anterior clinoidectomy, but accompanied only 8 of 19 selective clinoidectomies $(p=0.03)$. The extent of the actual clinoidectomy was predicted by the 3D-CTA-based preoperative planning in 17 of 27 cases (63.0\%). Particularly, prediction of the osteotomy was correct in $85.7 \%$ of complete, $62.5 \%$ of selective lateral, and $57.1 \%$ of medial clinoidectomy. None of the radiological and clinical factors determined the correlation between the planned and the actual extent of ACP removal. There was one incomplete occlusion among 23 obtained follow-up CTAs.
\end{abstract}

Conclusions. The predictive value of 3D-CTA on the extent of anterior clinoidectomy still remains unsatisfactory; it is limited by the individual variability of COA and its surrounding structures.

Clinical implications: Currently, the role of 3D-CTA planning is restricted to educational purposes only.

Key words: cerebral aneurysm, carotid-ophthalmic aneurysm, paraclinoid aneurysm, internal carotid artery, head computerised tomography angiography, anterior clinoid process, surgical clipping

(Neurol Neurochir Pol 2020; 54 (2): 138-149)

Address for correspondence: Tomasz Szmuda, Neurosurgery Department, Medical University of Gdansk, Dębinki 7 str., 80-952 Gdansk, Poland,

e-mail: tszmuda@gumed.edu.pl 


\section{Introduction}

Carotid-ophthalmic aneurysms (COAs) are uncommon vascular lesions which rarely rupture [1-6]. Various aneurysms of the proximal segment of the internal carotid artery (ICA) comprise COAs, including: paraclinoid aneurysms originating at the ophthalmic artery (true carotid-ophthalmic aneurysms), superior hypophyseal artery aneurysms and blood blister-like aneurysms located at the non-branching portion of the ICA.

Although these aneurysms can be secured either by surgical or endovascular methods, no consensus on the best treatment option has been established yet [1,4]. It is important for neurosurgeons to evaluate the potential risks and benefits of surgical clipping with the patient, while keeping in mind that most patients prefer a less invasive endovascular approach [6]. Since most COAs are diagnosed before rupture, surgical techniques need to be constantly improved to optimise patient outcome [7].

In the majority of cases, the neck of COA hides under the ACP which obstructs it. The close proximity and number of neurovascular structures around the ACP - the internal carotid artery inferomedially, the optic strut anteromedially, and the cavernous sinus inferolaterally - requires preoperative planning on ACP removal $[8,9]$. Selective or total removal of the anterior clinoid process (ACP) - also called anterior clinoidectomy - is a critical step that provides better exposure of the entire COA as the COA adjoins the ACP. Safe aneurysm clipping is facilitated by clinoidectomy together with optic canal unroofing $[3,7,10-12]$. ACP removal enables proximal control of the aneurysm which is necessary in premature rupture of the aneurysm, and also allows for improved exposure of the ophthalmic segment of the internal carotid artery [13]. A variety of well-established anterior clinoidectomy techniques - each with their pros and cons - have been reported over the years and can be divided into extradural, intradural, or hybrid [3, $8,10,11,14-17]$. Unfortunately, anterior clinoidectomy can result in severe complications such as direct or thermal ON injury, laceration of ICA trunk or its branches, and postoperative cerebrospinal fluid leakage leading to rhinorrhoea [18-20]. Some authors have also associated postoperative headaches with anterior clinoidectomy $[21,22]$. Therefore, the extent of skull base resection, including $\mathrm{ACP}$ and $\mathrm{ON}$ unroofing, should be precisely defined and anticipated to provide optimal space for safe aneurysm clipping.

\section{Clinical rationale for study}

Preoperative planning of ACP removal is essential as the benefits of a safer clipping procedure counterbalance the risk of severe complications. Historically, Ochiai et al. attempted to predict ACP removal preoperatively based on conventional angiography [23]. Today, multidetector-row computerised tomography angiography (CTA) display the three-dimensional modelling of COA and its surrounding structures. Only a few researchers have attempted to preoperatively predict the necessity of clinoidectomy prior to surgery of COA and have used CTA-based three-dimensional reconstructions (3D-CTA) for this purpose only $[14,24,25]$. Previous studies have measured various distances on CTA, even though this was difficult due to the anatomical variations encountered [5, 22, 24-26]. Together with the support of visualisation techniques like 3D-CTA, the effective planning of cranial base osteotomy can contribute to better surgical results $[14,25,27]$.

Will pre-operative 3D-CTA help predict the extent of anterior clinoidectomy? The aim of this study was to analyse 34 patients with COAs in need of surgical clipping and to predict whether 3D-CTA could be used not only for educational purposes, but also in a clinical setting.

\section{Materials and methods}

In this single-centre, prospective, observational, and cohort study 34 patients underwent surgical clipping of saccular COAs in the Neurosurgery Department of the Medical University of Gdańsk, Poland, between January 2012 and December 2018, following the exclusion of patients qualified for endovascular arm. COAs were defined as: located distal to the proximal dural ring and proximal to PCoA including clinoidal aneurysms (C5 segment of ICA according to the Bouthillier et al. classification [28]), anterior and posterior wall aneurysms, and originating at ophthalmic artery and superior hypophyseal artery (a subset of C6 segment of ICA according to the Bouthillier et al. classification [28]). Blood blister-like aneurysms were excluded. Inclusion criteria included: (1) patients who presented with either ruptured or unruptured saccular COA aneurysm; (2) patients who underwent CTA before surgery; and (3) patients in whom direct clipping following ACP removal was planned.

Multidetector-row, high-resolution head CT and contrast-enhanced CTA scans were acquired on LightSpeed VCT (General Electric Healthcare, Milwaukee, WI, USA). Slice thickness was $0.625 \mathrm{~mm}$, field-of-view was $512 \times 512$. We used three contrast agents interchangeably: iohexol (Omnipaque, Amersham Health, Princeton, NJ, USA), jomeprol (Patheon, Ferentino, Italy) and iopromidum (Bayer AG, Leverkusen, Germany). All the examinations were verified by two neurosurgeons (the first two named authors of this study) who also operated upon all the patients together. StealthViz (Medtronic Inc., Minneapolis, MN, USA) and RadiAnt DICOM Viewer (Medixant, Poznan, Poland) were used for the three-dimensional volume-rendered reconstructions of CTA data and preoperative planning of further osteotomy. The angle of view on the ACP and aneurysm was adjusted to the normal surgical perspective through the frontotemporal approach following minimal brain retraction. Multiplanar reconstructions of plain CTA images were also viewed and analysed.

Following consensus between the surgeons, virtually planned total and selective clinoidectomy were the two main 
endpoints of the study. Preoperative virtual clinoidectomy was attempted based on 3D-CTA using the plane resembling the pterional craniotomy. We evaluated the visibility of the aneurysm neck and virtually removed a part or the entire ACP from the 3D-CTA model. The two surgeons discussed and reached a consensus on the proper extent of clinoidectomy that would allow for a safe surgical clipping procedure. This decision was made by the first two authors as they were also the first two surgeons performing the procedures. At the time of publication, their neurosurgical experience was more than 30 years and more than 10 years respectively. A virtual partial or total clinoidectomy was performed prior to the surgery in all cases and the ACP removal was tailored to each patient. Lastly, the virtual clinoidectomy was compared to the actual clinoidectomy made during the surgery.

Photographs were captured from videos of the surgeries which were recorded on an OPMI Pentero microscope (Carl Zeiss Inc., Gottingen, Germany).

Conventional angiography was attained, although it was not used for the purpose of the current study. In our centre, CTA together with 3D-CTA were regarded as sufficient imaging of both the aneurysm and the critical surrounding structures such as ICA and ACP.

Factors that might have influenced the extent of the resection of the ACP (selective or complete) were recorded as follows: sex, age, symptoms, and aneurysm rupture status. Radiographic aneurysm characteristics included: aneurysm side, its predominant projection, width, height, neck size, aspect ratio and the bottleneck factor. Details of surgery collected from the recorded videos were as follows: premature rupture, temporary clipping (proximal/cervical ICA), suction decompression, number of permanent clips, their shape, additional wrapping and ACP-related complications. Radiological outcomes were classified as complete or incomplete, and aneurysm occlusion was based on a one-year follow-up CTA.

\section{Surgical management}

The common, external carotid arteries and cervical ICA were reserved for temporary closing in the neck region in every patient, prior to frontotemporal craniotomy (typically: anticlockwise head rotation 35-45 degrees, head of bed 1015 degrees, head extension 15-20 degrees). The Sylvian fissure was split, followed by frontal lobe retraction (and occasionally temporal lobe retraction), and the opticocarotid triangle was opened (with a sharp or blunt dissection). Next, the falciform ligament was incised by microscissors. Following the incision of the dura over the optic canal (dural U-shaped flap), the ON was unroofed if needed by using a diamond drill and/or a micro-rongeur. For the purpose of ACP removal, we used two- or three-millimetre diamond or coarse burr drills; sometimes we used a micro-punch or micro-rongeur instead. The extent of performed anterior clinoidectomy was tailored to the current intraoperative circumstances and requirements, was limited to the necessary exposure of the aneurysm neck, and finally was the operating surgeon's decision within the circumstances. Clip ligation of the neck of COA was the primary intention of the surgery, although gauze, cotton or dura were occasionally considered as wrapping material for aneurysm remnants.

\section{Patients and aneurysm characteristics}

There were 15 females (53.6\%) and 13 males (46.4\%), and the median and mean ages were 58 and $55.6(\mathrm{SD} \pm 11.7$, range 29-73) years respectively. Four patients (14.3\%) were admitted with aneurysmal subarachnoid haemorrhage, and the rest ( $\mathrm{n}=$ $24,85.7 \%$ ) were operated due to unruptured aneurysms. COA was diagnosed incidentally in 13 patients (46.4\%). Despite four patients (14.3\%) complaining of visual deficits, visual field testing confirmed a defect in only two of them (7.1\%). One aneurysm (3.6\%) was giant, two (7.1\%) were large, and the rest were smaller according to the contemporary classification. Mean values of the detailed sizes of the aneurysms in millimetres were as follows: width 7.96 (SD \pm 3.40 ), height 9.11 $(\mathrm{SD} \pm 5.78)$, neck size $4.92(\mathrm{SD} \pm 1.35)$, aspect ratio 1.85 $(\mathrm{SD} \pm 0.99)$, and bottleneck factor $1.55(\mathrm{SD} \pm 0.63)$. Aneurysms predominantly projected superolateral $(\mathrm{n}=14,50 \%)$ and superior $(n=7,25 \%)$. COAs were associated with other aneurysm(s) in nine angiograms (32.1\%) (Fig. 1, Tab. 1).

\section{Statistical methods}

Standard statistical methods were used for all the calculations. Descriptive statistics for continuous variables covered mean, median, range and standard deviation. Categorical variables were compared by means of Chi-square, respectively with or without Yates correction for continuity; U Mann-Whitney tests were applied for numerical values. Logistic regression of valid comparisons was attempted, though not performed due to an insufficient number of significant comparisons. A p value below 0.05 was determined significant. Software

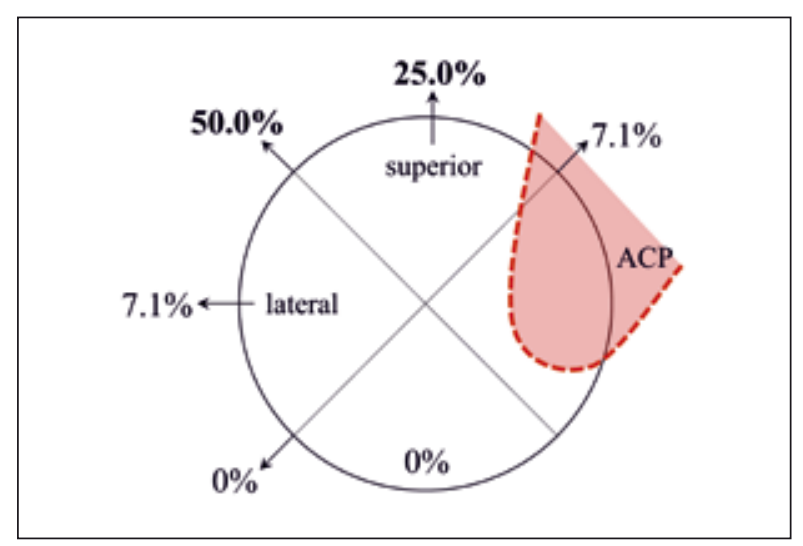

Figure 1. Graphical illustration of distribution of various projections of carotid-ophthalmic aneurysms. Three quarters of all aneurysms projected superolateral or superior. $\mathrm{ACP}$ - anterior clinoid process 


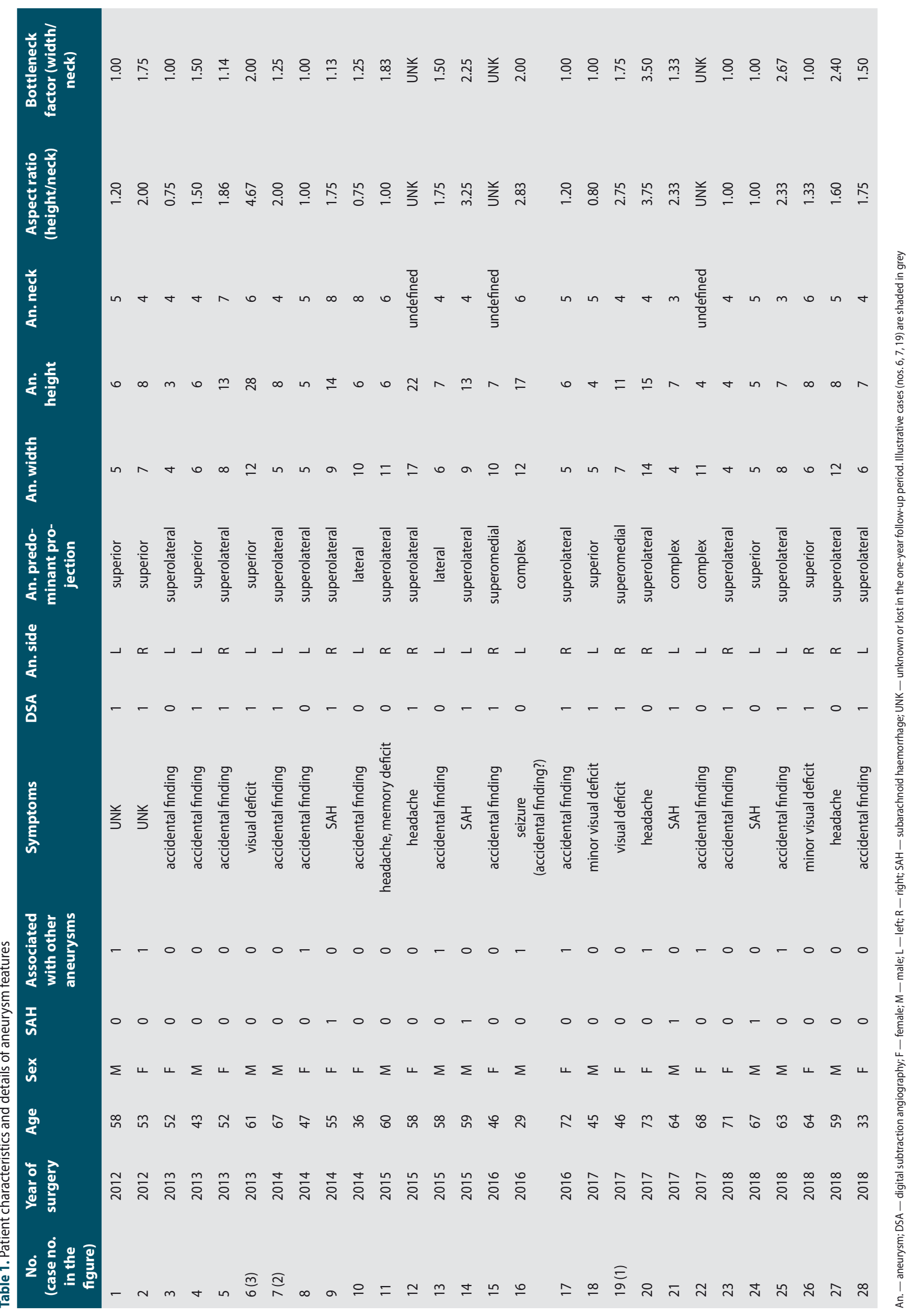


Statistica v. 10.0 (StatSoft Co, Tulsa, OK, USA) and Prism v. 6.07 (GraphPad Software, La Jolla, CA, USA) were used.

\section{Results}

\section{Anterior clinoidectomy and $\mathrm{ON}$ unroofing}

28 individuals met the inclusion criteria for this study. Intradural anterior clinoidectomy was applied in all our cases of COAs. Prior to the final clipping, the ACP was selectively removed in 19 cases $(67.9 \%)$, completely removed in seven cases $(25.0 \%)$ and remained intact in two cases (7.1\%). One prematurely ruptured superolateral COA was successfully secured, without the intended anterior clinoidectomy. Moreover, the selective clinoidectomy enabled temporary clipping of the proximal ICA only in two cases, one with the aneurysm projecting laterally, and one with the aneurysm projecting superiorly. When partial clinoidectomy facilitated clipping, drilling was discontinued as soon as safe clipping was feasible. We did not encounter any complications which could be directly attributed to the encroached ACP. The ON was released by its unroofing in 15 patients (53.6\%) and was always accompanied with total anterior clinoidectomy (7 of 7). $\mathrm{ON}$ unroofing was less often performed in selective ACP removal ( 8 of $19,42.1 \%, p=0.03$ ). We recognised that superolateral projection and lack of visual deficit were associated with both selective anterior clinoidectomy and $\mathrm{ON}$ unroofing $(\mathrm{p}<0.05)$ (Tab. 2, Tab. 3).

\section{Prediction of anterior clinoidectomy}

Preoperative planning corresponded with the extent of actual anterior clinoidectomy in the majority of cases (17 of 27 patients, 63.0\%). However, one patient - with a small superolateral COA - had no consensus upon the anticipated clinoidectomy ( 1 of $28,3.6 \%$ ). The ACP was selectively resected in 11 of $18(61.1 \%)$ patients whose osteotomy was suggested before surgery. CTA was performed preoperatively in 28 of our patients $(82.4 \%)$. The majority of our predictions were correct in both selective lateral and selective medial clinoidectomy, in 5 of $8(62.5 \%)$ and 4 of $7(57.1 \%)$ cases respectively ( $p=0.83)$. CTA-based planning was proven useful in 6 of 7 cases $(85.7 \%)$ when complete anterior clinoidectomy was performed. The difference in predictive value of 3D-CTA planning between selective and complete clinoidectomy was not significant $(\mathrm{p}=0.48)$. None of the analysed factors determined the preciseness of virtual planning of ACP removal ( $p>0.05)$ (Fig. 2, Tab. 4).

\section{Aneurysm clipping}

A few details of the five surgeries (17.9\%) were incomplete, either because the data was not initially collected or because the surgical protocols did not cover the wider scope of the procedure. All 28 aneurysms were finally clipped, although the unsecured remnant was additionally wrapped in three cases (10.7\%). Considering accessory techniques, the cervical ICA was temporarily clamped in half of the patients, and suction decompression through the superior thyroid artery facilitated neck clipping of two COAs (7.1\%). Radiological follow-up (CTA) was obtained for 23 individuals, revealing a single occurrence of significant incomplete occlusion (4.3\%). Our study did not aim to evaluate the clinical outcome.

\section{ACP removal with a $3 D$-CTA model affecting surgery}

In order to clip the aneurysm, partial or total ACP removal was necessary in all our cases. Fortunately, no complications intraoperatively or postoperatively were encountered due to clinoidectomy. ACP removal lengthened the duration of surgery, although this was not compared to any control group. The 3D-CTA model was accessible during every surgery, and was used in the operating theatre as a visualisation adjunct: to visualise the aneurysm, surrounding bony structures and anatomical relationships. The focus of the surgeons remained primarily on the aneurysm under the microscopic field. 3D-CTA did not affect the surgery, as the required osteotomy was tailored to the intraoperative findings; therefore, the extent of osteotomy was unpredictable in about $37.5 \%$ of cases.

\section{Discussion}

Although we hypothesised that 3D-CTA would be useful in planning COA surgeries, we found that the predictive value of 3D-CTA regarding the extent of the ACP removal remains unsatisfactory, as only $60 \%$ of the predictions were correct. However, the prediction of complete clinoidectomy was rather more reliable at $85.7 \%$ - while much lower in selective lateral and medial clinoidectomy at $62.5 \%$ and $57.1 \%$ respectively. These results could be misinterpreted by some because $3 \mathrm{D}$ -CTA can only be used to predict complete clinoidectomy and remains limited in predicting a selective clinoidectomy. 3D-CTA did not reach our expectations; therefore, our results do not allow us to recommend 3D-CTA in predicting the extent of clinoidectomy in a clinical setting.

Nonetheless, in some specific anatomical variants we anticipate that these visualisation techniques will have better accuracy. It was impossible to select a subgroup of our patients with better prediction rates, as all the examined factors in our study did not influence the accuracy of the prediction.

Various shapes, projections and sizes of COAs, together with varying ACP anatomy, pneumatisation, and route of pneumatisation make it impossible to attain a single universal approach towards clinoidectomy. We initially tried to overcome an individual's anatomical variability by planning the extent of anticipated clinoidectomy on an individual basis; however, it was unsuccessful. 3D-CTA-based preoperative visualisation remains essential to view the aneurysm, ICA and surrounding bony structures $[14,24,25,27]$.

Ochiai et al. were the first to attempt to predict ACP removal preoperatively based on conventional angiography, as that was the only accessible imaging tool until 1989 [2]. However, 
Table 2. Factors associated with the necessity of various cranial base osteotomies

\begin{tabular}{|c|c|c|c|c|}
\hline \multirow[t]{2}{*}{ Factor } & \multicolumn{2}{|c|}{ Anterior clinoidectomy } & \multicolumn{2}{|c|}{ Optic nerve unroofing } \\
\hline & Total & Selective & Yes & No \\
\hline \multirow[t]{2}{*}{ Age (mean $\pm S D)$} & $53.0 \pm 8.2$ & $58.1 \pm 12.0$ & $55.5 \pm 11.6$ & $55.9 \pm 12.2$ \\
\hline & \multicolumn{2}{|c|}{$p=0.19$} & \multicolumn{2}{|c|}{$p=0.92$} \\
\hline \multirow[t]{2}{*}{ Sex (n, \% of females) } & $3 / 7,42.9 \%$ & $10 / 19,52.6 \%$ & $7 / 15,46.7 \%$ & $8 / 13,61.5 \%$ \\
\hline & \multicolumn{2}{|c|}{$p=1.00$} & \multicolumn{2}{|c|}{$p=0.68$} \\
\hline \multirow[t]{2}{*}{ Multiple aneurysm occurrence (n, \%) } & $2 / 7,28.6 \%$ & $7 / 19,36.8 \%$ & $4 / 15,26.7 \%$ & $5 / 13,38.5 \%$ \\
\hline & \multicolumn{2}{|c|}{$p=0.94$} & \multicolumn{2}{|c|}{$p=0.79$} \\
\hline \multicolumn{5}{|l|}{ Symptoms } \\
\hline \multirow[t]{2}{*}{$\mathrm{SAH}(\mathrm{n}, \%)$} & $1 / 7,14.3 \%$ & $3 / 19,15.8 \%$ & $2 / 15,13.3 \%$ & $2 / 13,15.4 \%$ \\
\hline & \multicolumn{2}{|c|}{$p=0.60$} & \multicolumn{2}{|c|}{$p=0.70$} \\
\hline \multirow[t]{2}{*}{ visual deficit (n, \%) } & $2 / 4,50.0 \%$ & $0 / 16,0 \%$ & $2 / 11,18.2 \%$ & $0 / 11,0 \%$ \\
\hline & \multicolumn{2}{|c|}{$p=0.04$} & \multicolumn{2}{|c|}{$\mathrm{p}<0.01$} \\
\hline \multicolumn{5}{|l|}{ Aneurysm } \\
\hline \multirow[t]{2}{*}{ DSA performed before surgery $(n, \%)$} & $7 / 7,100 \%$ & $10 / 19,52.6 \%$ & $11 / 15,73.3 \%$ & $7 / 13,53.9 \%$ \\
\hline & \multicolumn{2}{|c|}{$p=0.07$} & & \\
\hline side ( $n, \%$ of left) & $4 / 7,57.1 \%$ & $10 / 19,52.6 \%$ & $8 / 15,53.3 \%$ & $8 / 13,61.5 \%$ \\
\hline & & & & \\
\hline superolateral projection (n, \%) & $0 / 7,0 \%$ & $12 / 19,63.1 \%$ & $3 / 15,20.0 \%$ & $11 / 13,84.6 \%$ \\
\hline & & & & \\
\hline width (mean \pm SD) & $7.29 \pm 2.81$ & $8.53 \pm 3.63$ & $8.20 \pm 3.88$ & $7.69 \pm 2.89$ \\
\hline & & & & \\
\hline height (mean \pm SD) & $10.43 \pm$ & $9.05 \pm 5.11$ & $9.67 \pm 7.13$ & $8.46 \pm 3.89$ \\
\hline & & & & \\
\hline neck size (mean $\pm \mathrm{SD})$ & $4.33 \pm 1.03$ & $5.24 \pm 1.44$ & $4.75 \pm 0.97$ & $5.08 \pm 1.66$ \\
\hline & & & & \\
\hline aspect ratio (mean $\pm S D$ ) & $2.41 \pm 1.24$ & $1.72 \pm 0.88$ & $1.92 \pm 1.10$ & $1.78 \pm 0.92$ \\
\hline & & & & \\
\hline bottleneck factor (mean $\pm S D$ ) & $1.56 \pm 0.36$ & $1.58 \pm 0.74$ & $1.48 \pm 0.50$ & $1.62 \pm 0.76$ \\
\hline & & & & \\
\hline Clipping & & & & \\
\hline additional wrapping (n, \%) & $2 / 7,28.6 \%$ & $1 / 19,5.3 \%$ & $2 / 15,13.3 \%$ & $1 / 13,7.7 \%$ \\
\hline & & & & \\
\hline premature rupture $(n, \%)$ & $1 / 7,14.3 \%$ & $1 / 19,5.3 \%$ & $1 / 15,6.7 \%$ & $1 / 13,7.7 \%$ \\
\hline & & & & \\
\hline temporary clipping & & & & \\
\hline cervical ICA (n, \%) & $4 / 5,80.0 \%$ & $8 / 18,44.4 \%$ & $1 / 15,6.7 \%$ & $1 / 13,7.7 \%$ \\
\hline & & & & \\
\hline proximal ICA (n, \%) & $0 / 7,0 \%$ & $2 / 19,10.5 \%$ & $8 / 13,61.5 \%$ & $4 / 11,36.4 \%$ \\
\hline & & & & \\
\hline suction decompression (n, \%) & $0 / 4,0 \%$ & $2 / 18,11.1 \%$ & $0 / 12,0 \%$ & $2 / 11,18.2 \%$ \\
\hline & & & & \\
\hline clip(s) shape ( $n, \%$ of angled clip) & $2 / 7,28.6 \%$ & $4 / 19,21.1 \%$ & $5 / 15,33.3 \%$ & $2 / 13,15.4 \%$ \\
\hline & & & & \\
\hline number of permanent clips (mean \pm SD) & $1.4 \pm 0.8$ & $1.4 \pm 0.8$ & $1.4 \pm 0.7$ & $1.3 \pm 0.9$ \\
\hline & & & & \\
\hline years from study initiation (mean $\pm S D$ ) & $2.3 \pm 2.3$ & $3.9 \pm 1.7$ & $3.8 \pm 2.2$ & $3.1 \pm 1.7$ \\
\hline & & & & \\
\hline complete occlusion in the FU $(n, \%)$ & $4 / 4,100 \%$ & $16 / 17,94.1 \%$ & $11 / 11,100 \%$ & $11 / 12,91.7 \%$ \\
\hline 象 & 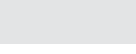 & 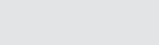 & 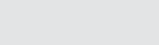 & \\
\hline
\end{tabular}

ACP - anterior clinoid process, DSA - digital subtraction angiography, ICA - internal carotid artery, SAH — subarachnoid haemorrhage, SD - standard deviation, FU — follow-up 


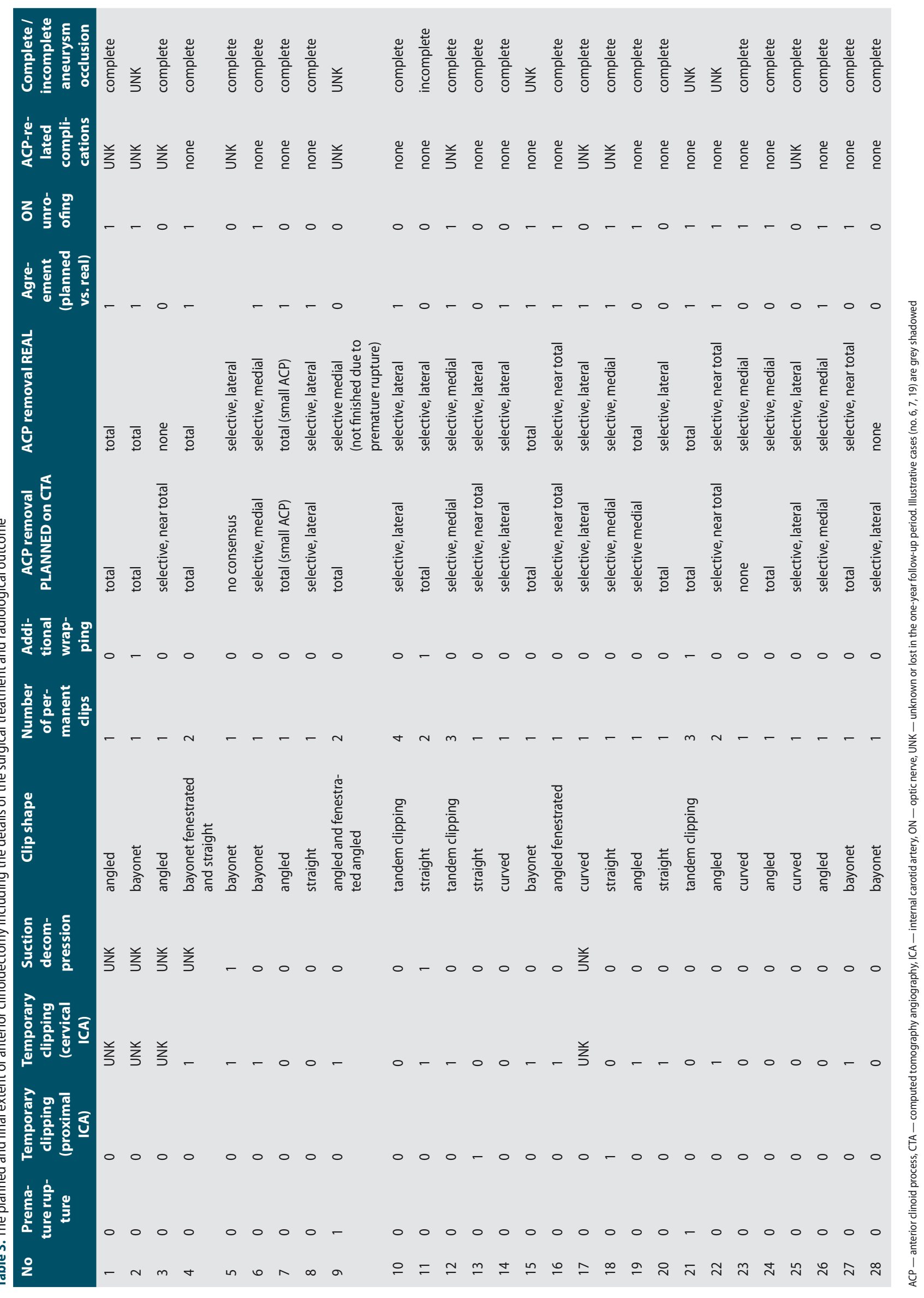




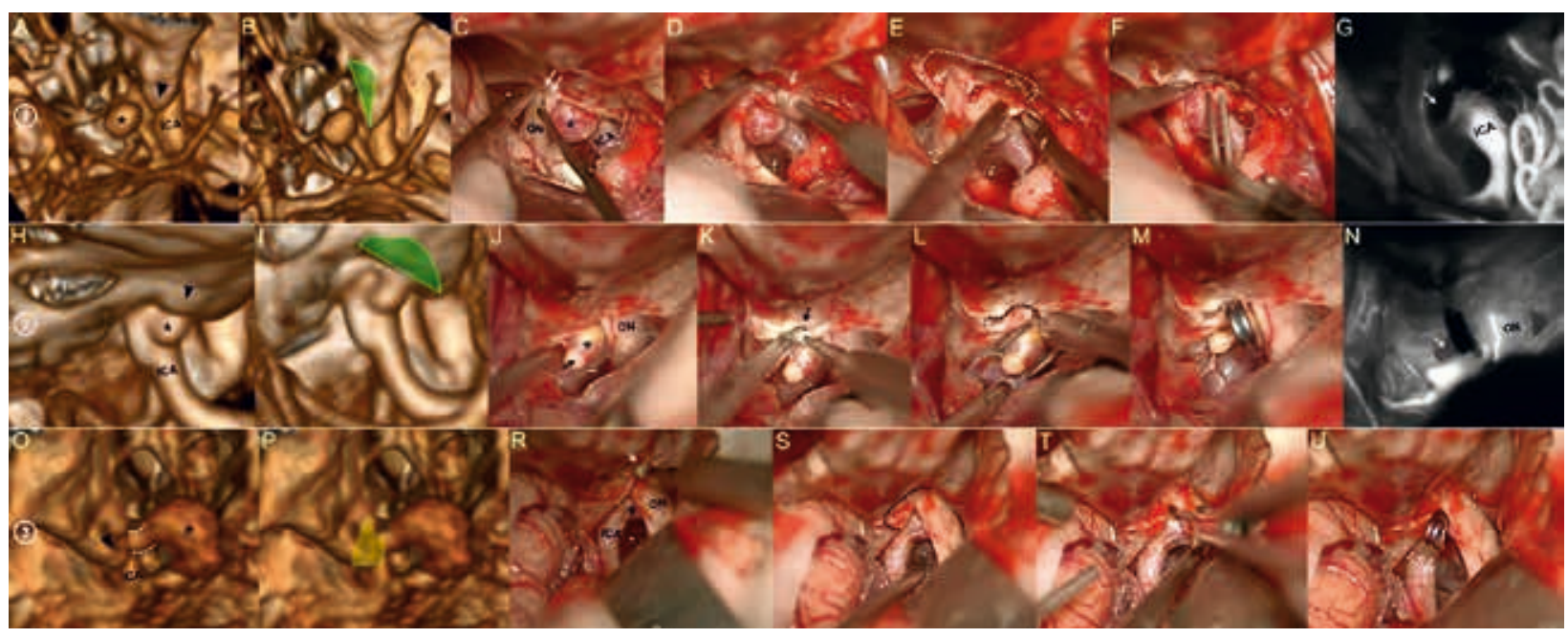

Figure 2. Illustrative cases. The extent of anterior clinoidectomy (marked in green or yellow) was planned on 3D-CTA before surgery (B, I, P). The anticipated clinoidectomy corresponded to performed osteotomy (dashed lines) (E, L, S) in cases 2 and 3. Line 1 (patient 19 in Tab. 1 and 2): the aneurysm (asterisk) projected superomedial. ACP (black arrowhead) was supposed to be selectively resected, although finally ON was unroofed (cutting the dural fold and the falciform ligament, white arrows) (C), the ACP was completely drilled (D) and the remainder of the dura was excised (E). The patency of ICA and occlusion of the aneurysm (arrow) was confirmed on videoangiography (ICG-Pulsion, Pulsion Medical, Munich, Germany) (G). Line 2 (patient 7 in Tab. 1 and 2): 3D-CTA incorrectly demonstrated the shape of the aneurysm (arrow J). Complete removal of the small ACP sufficed to successfully clip the aneurysm. Line 3 (patient 6 in Tab. 1 and 2): a giant complex aneurysm with a defined neck (dashed lines 0 ). ON unroofing $(R)$ with selective medial clinoidectomy was planned $(P)$ and performed; a dural flap covering the ACP was used to seal the remnant of the pneumatised ACP.

ACP - anterior clinoid process; ICA - internal carotid artery; ON - optic nerve; 3D-CTA - three-dimensional computerised tomography angiography

CTA now offers faster image acquisition, more coverage of the patient, and higher spatial resolution than before. Furthermore, 3D-CTA proves itself faster, cheaper and less invasive than digital subtraction angiography in determining the surgical indications in patients with intracranial aneurysms as well as its recommendation for all COAs [14, 27, 29]. No other study has combined the qualitative ability of $3 \mathrm{D}$-CTA to predict the extent of anterior clinoidectomy required in COAs. Therefore, we found it difficult to relate our results to other publications. Several papers have been published on the usefulness of CTA to preoperatively predict clinoidectomy when relating to posterior communicating artery (PCOM) aneurysm surgeries, but not COA [14, 23-25]. Park's study expanded Ochiai's research and proved that the distal ICA angle measured on classic angiography and 3D-CTA could help predict the necessity of anterior clinoidectomy [25]. The authors found consistency in the results, although the findings cannot be implemented into current practice as the exact threshold values were not provided. In the study by Kamide et al., the necessity of ACP removal was modified according to the distance from the ACP to the neck of the PCOM aneurysm, but this could not be compared to COAs, because all COAs lie far proximal to PCOM [24].

More research needs to be done on a larger population of patients to evaluate preoperative prediction on the extent of anterior clinoidectomy for clipping of COAs. The conclusions should be disseminated to other neurosurgeons so that 3D-CTA's potential use can be augmented by future research. Since our study was limited to only 28 cases, it should serve as a guide for future scientific research. However, due to the rarity of COAs in practice, it would be difficult for any other single hospital to collect a substantial amount of surgical cases to draw final conclusions. In the future, perhaps a merged CTA with MRA should be used, as the ON is not seen on CTA.

Today, 3D-CTA remains a valuable tool for neurosurgeons who want to better visualise the aneurysm, ICA and its surrounding bony structures, and especially for COAs. 3D-CTA can also prove useful in the visualisation of PCOM aneurysms and basilar apex aneurysms [14,24,25,30,31]. Due to the varying anatomy of aneurysms and the ACP, further research must be done by other neurosurgeons to investigate the use of 3D-CTA on the predictive value of safe anterior clinoidectomies, as this will ultimately enhance patient safety.

For future studies, 3D-CTA could be used to measure the distance between the anatomical landmarks to see if they can augment our predictions. For example, in PCOM aneurysms, the distances from the ACP tip and the ACP line to the aneurysmal proximal neck predicted whether anterior clinoidectomy was required [24]. Preoperative CT has also proven to detect anatomic variations of the ACP - such as a caroticoclinoid foramen, interclinoid osseous bridge, and pneumatisation of the ACP [14]. Attaining information about anatomical 
Table 4. Factors influencing the accordance between the planned and actual extent of the anterior clinoidectomy

\begin{tabular}{|c|c|c|c|c|c|c|}
\hline \multirow[t]{2}{*}{ Factor } & \multicolumn{2}{|c|}{$\begin{array}{l}\text { Any extent of the } \\
\text { clinoidectomy }\end{array}$} & \multicolumn{2}{|c|}{$\begin{array}{l}\text { Complete } \\
\text { clinoidectomy }\end{array}$} & \multicolumn{2}{|c|}{$\begin{array}{c}\text { Selective } \\
\text { clinoidectomy }\end{array}$} \\
\hline & $\begin{array}{c}\text { Predicted on } \\
\text { CTA }\end{array}$ & Not predicted & $\begin{array}{c}\text { Predicted on } \\
\text { CTA }\end{array}$ & Not predicted & $\begin{array}{c}\text { Predicted on } \\
\text { CTA }\end{array}$ & Not predicted \\
\hline Age (mean $\pm S D$ ) & $\begin{array}{l}54.9 \pm 12.1 \\
p=0.69\end{array}$ & $57.4 \pm 11.9$ & $\begin{array}{l}54.2 \pm 8.4 \\
p=1.00\end{array}$ & $46.0 \pm E$ & $\begin{array}{l}55.3 \pm 14.0 \\
p=0.34\end{array}$ & $63.3 \pm 7.0$ \\
\hline Sex ( $n$, $\%$ of females) & $\begin{array}{l}8 / 17,47.1 \% \\
p=0.80\end{array}$ & $6 / 10,60.0 \%$ & $\begin{array}{l}2 / 6,33.3 \% \\
p=0.87\end{array}$ & $1 / 1,100 \%$ & $\begin{array}{l}6 / 11,54.5 \% \\
p=1.00\end{array}$ & $3 / 7,42.9 \%$ \\
\hline Multiple aneurysm occurrence (n, \%) & $\begin{array}{l}7 / 17,41.2 \% \\
p=0.48\end{array}$ & $2 / 10,20.0 \%$ & $\begin{array}{l}2 / 6,33.3 \% \\
p=0.61\end{array}$ & $0 / 1,0 \%$ & $\begin{array}{l}5 / 11,45.5 \% \\
p=0.82\end{array}$ & $2 / 7,28.6 \%$ \\
\hline Symptoms & & & & & & \\
\hline $\mathrm{SAH}(\mathrm{n}, \%)$ & $\begin{array}{l}2 / 17,11.8 \% \\
p=0.98\end{array}$ & $2 / 10,20.0 \%$ & $\begin{array}{l}1 / 6,16.7 \% \\
p=0.27\end{array}$ & $0 / 1,0 \%$ & $\begin{array}{l}1 / 11,9.1 \% \\
p=0.67\end{array}$ & $2 / 7,28.6 \%$ \\
\hline visual deficit (n, \%) & $\begin{array}{l}1 / 13,7.7 \% \\
p=0.69\end{array}$ & $1 / 8,12.5 \%$ & $\begin{array}{l}1 / 1,100 \% \\
p=1.00\end{array}$ & $1 / 3,33.3 \%$ & $\begin{array}{l}0 / 10,0 \% \\
p=1.00\end{array}$ & $0 / 5,0 \%$ \\
\hline Aneurysm & & & & & & \\
\hline DSA performed before surgery $(n, \%)$ & $\begin{array}{l}13 / 17,76.5 \% \\
p=0.14\end{array}$ & $4 / 10,40.0 \%$ & $\begin{array}{l}6 / 6,100 \% \\
p=\end{array}$ & $\begin{array}{l}1 / 1,100 \% \\
.00\end{array}$ & $\begin{array}{l}7 / 11,63.6 \% \\
p=0.33\end{array}$ & $2 / 7,28.6 \%$ \\
\hline side (n, \% of left) & $\begin{array}{l}12 / 17,70.6 \% \\
p=0.25\end{array}$ & $4 / 10,40.0 \%$ & $\begin{array}{l}4 / 6,66.7 \% \\
p=0.88\end{array}$ & $0 / 1,0 \%$ & $\begin{array}{l}8 / 11,72.7 \% \\
p=0.18\end{array}$ & $2 / 7,28.6 \%$ \\
\hline superolateral projection (n, \%) & $\begin{array}{l}6 / 17,35.3 \% \\
p=0.18\end{array}$ & $7 / 10,70.0 \%$ & $\begin{array}{l}0 / 6,0 \% \\
p=1.00\end{array}$ & $0 / 1,0 \%$ & $\begin{array}{l}6 / 11,54.6 \% \\
p=0.83\end{array}$ & $5 / 7,71.4 \%$ \\
\hline width (mean \pm SD) & $\begin{array}{l}8.06 \pm 3.54 \\
p=0.90\end{array}$ & $7.80 \pm 3.52$ & $\begin{array}{l}7.33 \pm 3.08 \\
p=1.00\end{array}$ & $7.00 \pm E$ & $\begin{array}{l}8.46 \pm 3.86 \\
p=0.85\end{array}$ & $8.71 \pm 3.82$ \\
\hline height (mean \pm SD) & $\begin{array}{l}9.53 \pm 6.72 \\
p=0.74\end{array}$ & $8.00 \pm 4.08$ & $\begin{array}{l}10.33 \pm 8.69 \\
p=1.00\end{array}$ & $11.00 \pm E$ & $\begin{array}{l}9.09 \pm 5.82 \\
p=1.00\end{array}$ & $8.43 \pm 4.35$ \\
\hline neck size (mean \pm SD) & $\begin{array}{l}4.86 \pm 1.35 \\
p=0.79\end{array}$ & $4.80 \pm 1.32$ & $\begin{array}{l}4.40 \pm 1.14 \\
p=1.00\end{array}$ & $4.00 \pm E$ & $\begin{array}{l}5.11 \pm 1.45 \\
p=0.96\end{array}$ & $5.14 \pm 1.46$ \\
\hline aspect ratio (mean \pm SD) & $\begin{array}{l}1.94 \pm 1.09 \\
p=0.58\end{array}$ & $1.71 \pm 0.92$ & $\begin{array}{l}2.34 \pm 1.37 \\
p=1.00\end{array}$ & $2.75 \pm E$ & $\begin{array}{l}1.72 \pm 0.91 \\
p=0.96\end{array}$ & $1.69 \pm 0.97$ \\
\hline bottleneck factor (mean \pm SD) & $\begin{array}{l}1.50 \pm 0.55 \\
p=0.75\end{array}$ & $1.66 \pm 0.79$ & $\begin{array}{l}1.52 \pm 0.38 \\
p=1.00\end{array}$ & $1.75 \pm E$ & $\begin{array}{l}1.49 \pm 0.64 \\
p=0.60\end{array}$ & $1.77 \pm 0.92$ \\
\hline Clipping & & & & & & \\
\hline additional wrapping (n, \%) & $\begin{array}{l}2 / 17,11.8 \% \\
p=0.62\end{array}$ & $1 / 10,10.0 \%$ & $\begin{array}{l}2 / 6,33.3 \% \\
p=0.61\end{array}$ & $0 / 1,0 \%$ & $\begin{array}{l}0 / 11,0 \% \\
p=0.81\end{array}$ & $1 / 7,14.3 \%$ \\
\hline ON unroofing (n, \%) & $\begin{array}{l}11 / 17,64.7 \% \\
p=0.40\end{array}$ & $4 / 10,40.0 \%$ & $\begin{array}{l}6 / 6,100 \% \\
p=1.00\end{array}$ & $1 / 1,100 \%$ & $\begin{array}{l}5 / 11,45.5 \% \\
p=0.71\end{array}$ & $3 / 7,42.9 \%$ \\
\hline premature rupture (n, \%) & $\begin{array}{l}1 / 17,5.9 \% \\
p=0.71\end{array}$ & $1 / 10,10.0 \%$ & $\begin{array}{l}1 / 6,16.7 \% \\
p=0.27\end{array}$ & $0 / 1,0 \%$ & $\begin{array}{l}0 / 11,0 \% \\
p=0.81\end{array}$ & $1 / 7,14.3 \%$ \\
\hline temporary clipping & & & & & & \\
\hline cervical ICA (n, \%) & $\begin{array}{l}6 / 14,42.9 \% \\
p=0.87\end{array}$ & $5 / 9,55.6 \%$ & $\begin{array}{l}3 / 4,75.0 \% \\
p=0.40\end{array}$ & $1 / 1,100 \%$ & $\begin{array}{l}3 / 10,30.0 \% \\
p=0.54\end{array}$ & $4 / 7,57.1 \%$ \\
\hline proximal ICA (n, \%) & $\begin{array}{l}1 / 17,5.9 \% \\
p=0.71\end{array}$ & $1 / 10,10.0 \%$ & $\begin{array}{l}0 / 6,0 \% \\
p=1.00\end{array}$ & $0 / 1,0 \%$ & $\begin{array}{l}1 / 11,9.1 \% \\
p=0.67\end{array}$ & $1 / 7,14.3 \%$ \\
\hline suction decompression (n, \%) & $\begin{array}{l}0 / 13,0 \% \\
p=0.85\end{array}$ & $1 / 9,11.1 \%$ & $\begin{array}{l}0 / 3,0 \% \\
p=1.00\end{array}$ & $0 / 1,0 \%$ & $\begin{array}{l}0 / 10,0 \% \\
p=0.85\end{array}$ & $1 / 7,14.3 \%$ \\
\hline clip(s) shape ( $n, \%$ of angled clip) & $\begin{array}{l}4 / 17,23.5 \% \\
p=0.52\end{array}$ & $3 / 10,30.0 \%$ & $\begin{array}{l}1 / 6,16.7 \% \\
p=0.89\end{array}$ & $1 / 1,100 \%$ & $\begin{array}{l}3 / 11,27.3 \% \\
p=0.46\end{array}$ & $1 / 7,14.3 \%$ \\
\hline number of permanent clips (mean $\pm S D$ ) & $\begin{array}{l}1.5 \pm 0.9 \\
p=0.60\end{array}$ & $1.2 \pm 0.4$ & $\begin{array}{l}1.5 \pm 0.8 \\
p=1.00\end{array}$ & $1.0 \pm E$ & $\begin{array}{l}1.5 \pm 1.0 \\
p=0.93\end{array}$ & $1.3 \pm 0.5$ \\
\hline $\begin{array}{l}\text { years from study initiation (mean } \pm \\
\text { SD) }\end{array}$ & $3.1 \pm 1.9$ & $4.3 \pm 1.8$ & $1.8 \pm 2.1$ & $5.0 \pm E$ & $3.8 \pm 1.5$ & $4.4 \pm 1.7$ \\
\hline & $p=0.13$ & & $p=1.00$ & & $p=0.44$ & \\
\hline complete occlusion in the FU $(n, \%)$ & $\begin{array}{l}0 / 13,0 \% \\
p=0.85\end{array}$ & $1 / 9,11.1 \%$ & $\begin{array}{l}0 / 3,0 \% \\
p=1.00\end{array}$ & $0 / 1,0 \%$ & $\begin{array}{l}0 / 10,0 \% \\
p=0.79\end{array}$ & $1 / 6,16.7 \%$ \\
\hline
\end{tabular}

ACP - anterior clinoid process, DSA - digital subtraction angiography, E - erroneous value due to insufficient number of valid data, ICA - internal carotid artery, ON - optic nerve, SAH - subarachnoid haemorrhage, SD — standard deviation, FU — follow-up 
variations can be of great value to the neurosurgeon as he can then take the precautions necessary for safer and less invasive surgery. It is difficult to suggest universal quantitative values to use in every COA procedure as there is great anatomical variability in both the ACP configuration, pneumatisation and an aneurysm's shape, size, and projection $[9,32]$. Every individual case should be evaluated preoperatively to plan not only the extent of ACP removal, but also clip selection and positioning.

Intradural anterior clinoidectomy was applied in all our cases of COAs. Since Dolenc described the technique of extradural anterior clinoidectomy [33], both extradural and intradural approaches have been tested, although the best technique is still unclear $[3,16,22]$. Some neurosurgeons have postulated that the preferred approach depends on the particular pathology $[17,34]$. For example, an exclusively intradural approach is best when used in the treatment of paraclinoid aneurysms as it allows for a better view of the aneurysm and management of its surrounding structures [17]. An extradural approach is effective against large tumours surrounding the $\mathrm{ON}$ and the infrachiasmatic space, as has been shown and verified during some procedures [10,35]. Regardless of which approach is used, drilling very close to ICA and ON can lead to catastrophic complications [18-20]. The 'no drill' technique offers a more conservative approach to anterior clinoidectomy and optic canal unroofing by eliminating the risks of thermal injury and ultrasound-associated cranial neuropathies [36]. ON damage, oculomotor nerve damage, and aneurysm rupture have been described by others, although no such complications occurred in our series $[18,19,37]$. While these complications are rare, ON injury is less common with the intradural technique, because of early visualisation and drilling further away from the ON. Oculomotor nerve injury is more common in the intradural approach [8]. Limiting the extent of the required anterior clinoidectomy for subjectively assessed safe clip placement could reduce the complication rate and limit the temperature effects of drilling $[20,38]$.

Another issue that could potentially limit ACP clinoidectomy is haemorrhage from the cavernous sinus, as the ACP often communicates with this vascular structure [10]. However, a complete clinoidectomy provides an area two times greater than the selective ACP [22]. On the other hand, selective clinoidectomy was sufficient to clip $86.4 \%$ of 81 COAs in one study [39]. Proximal control was the target in tailored ACP removal in a Finnish series, although in our opinion it did not show an advantage as the cervical ICA could be temporarily occluded without an extensive cranial base osteotomy [10]. These studies prove that both patient-specific variables and a surgeon's own preferences influence the actual extent of clinoidectomy. This all makes preoperative visualisation via 3D-CTA unpredictable.

Our study was subject to some limitations. Two neurosurgeons performed all the surgeries that were included in this study over the course of six years. Due to the duration of our study, one can assume that the proficiency and analysis of 3D-CTA changed over this period, influencing both the anticipated clinoidectomy and the actual clinoidectomy. We took the year of surgery into factor analysis and found that it did not influence the results. Moreover, two surgeons planned their own surgeries, so it could be misinterpreted as a bias of inter-rater variability on the surgical approach of ACP removal. After all, a surgeon's approach to ACP removal and surgery preferences would necessitate a varying degree of the clinoid space to be formed. In our study, the plan of a given surgery and ACP removal was always performed by the same surgeons who were going to operate upon the patient because each individual surgeon is aware of his or her strengths and weaknesses and can therefore plan the clinoidectomy in the way which suits their honed manual preferences.

We believe that if the basic skills of the individual neurosurgeon cannot be utilised to their optimal potential, the predictive value of 3D-CTA on clinoidectomy becomes an extraneous detail. Therefore, we stress that having two surgeons plan their own surgeries is not a drawback, but a deliberate choice.

\section{Clinical implications / future directions}

In this 34-patient study, we found that the predictive value of $3 \mathrm{D}$-CTA on the extent of anterior clinoidectomy remains unsatisfactory. However, 3D-CTA remains a valuable tool to better visualise the aneurysm, ICA and surrounding bony structures. The ON could possibly be visualised on CTA with targeted settings and a modified window, but it is difficult to reconstruct the $\mathrm{ON}$, bones and vessels all in one window. Therefore, we intend to merge CTA with MRI/MRA in a future prospective study. Perhaps a merged CTA with MRA should be used because the $\mathrm{ON}$ is not seen on CTA alone.

Lastly, measuring the distance between anatomical landmarks relating to the $\mathrm{ACP}$ and other neurovascular structures could indicate whether an anterior clinoidectomy is required. These measurements could help highlight and categorise the anatomical variances of the ACP and neighbouring structures.

\footnotetext{
Supplementary video to the manuscript: https://vimeo. com/356693143

Funding: No funding was received for this research

Conflicts of interest: All authors certify that they have no affiliation with or involvement in any organisation or entity with any financial interest (such as honoraria; educational grants; participation in speakers' bureaux; membership, employment, consultancies, stock ownership, or other equity interest; and expert testimony or patent-licensing arrangements), or non-financial interest (such as personal or professional relationships, affiliations, knowledge or beliefs) in the subject matter or materials discussed in this manuscript

Ethical permission: For preparation of this and previous articles, ethical approval was obtained in the institution (IRB Committee number: NKEBN/209/2008)
} 
Informed consent: Informed consent for treatment and data processing was obtained from all individual participants included in this study

\section{Abbreviations and acronyms:}

ACP - anterior clinoid process

$\mathrm{COA}$ - carotid-ophthalmic aneurysm

$\mathrm{CTA}-$ computerised tomography angiography

3D-CTA - three-dimensional computerised tomography

angiography

ICA - internal carotid artery

ON - optic nerve

PCOM - posterior communicating artery

LSO - lateral supraorbital

\section{References:}

1. Falk Delgado A, Andersson T, Falk Delgado A. Ruptured carotid-ophthalmic aneurysm treatment: a non-inferiority meta-analysis comparing endovascular coiling and surgical clipping. Br J Neurosurg. 2017; 31(3): 345-349, doi: 10.1080/02688697.2017.1297371, indexed in Pubmed: 28637115.

2. Orlický M, Sameš M, Hejčl A, et al. Carotid-ophthalmic aneurysms-Our results and treatment strategy. Br J Neurosurg. 2015; 29(2): $237-$ 242, doi: 10.3109/02688697.2014.976176, indexed in Pubmed: 25365665.

3. Sai Kiran NA, Sivaraju L, Vidyasagar K, et al. Intradural "limited drill" technique of anterior clinoidectomy and optic canal unroofing for microneurosurgical management of ophthalmic segment and PCOM aneurysms-review of surgical results. Neurosurg Rev. 2018 [Epub ahead of print], doi: 10.1007/s10143-018-1054-x, indexed in Pubmed: 30483973.

4. Kamide T, Tabani H, Safaee MM, et al. Microsurgical clipping of ophthalmic artery aneurysms: surgical results and visual outcomes with 208 aneurysms. J Neurosurg. 2018; 129(6): 1511-1521, doi: 10.3171/2017.7.JNS17673, indexed in Pubmed: 29372879.

5. Rafiei A, Hafez A, Jahromi BR, et al. Anatomic Features of Paraclinoid Aneurysms: Computed Tomography Angiography Study of 144 Aneurysms in 136 Consecutive Patients. Neurosurgery. 2017; 81(6): 949957, doi: 10.1093/neuros/nyx157, indexed in Pubmed: 28419295.

6. Lindgren A, Vergouwen MDI, van der Schaaf I, et al. Endovascular coiling versus neurosurgical clipping for people with aneurysmal subarachnoid haemorrhage. Cochrane Database Syst Rev. 2018; 8: CD003085, doi: 10.1002/14651858.CD003085.pub3, indexed in Pubmed: 30110521.

7. Kimura T, Morita A. Early Visualization of Optic Canal for Safe Anterior Clinoidectomy: Operative Technique and Supporting Computed Tomography Findings. World Neurosurg. 2019; 126: e447-e452, doi: 10.1016/j.wneu.2019.02.071, indexed in Pubmed: 30825628.

8. Kulwin C, Tubbs RS, Cohen-Gadol AA. Anterior clinoidectomy: Description of an alternative hybrid method and a review of the current techniques with an emphasis on complication avoidance. Surg Neurol Int. 2011; 2: 140, doi: 10.4103/2152-7806.85981, indexed in Pubmed: 22059135.

9. Szmuda T, Sloniewski P, Baczalska A, et al. The pneumatisation of anterior clinoid process is not associated with any predictors that might be recognised preoperatively. Folia Morphol (Warsz). 2013; 72(2): 100-106, doi: 10.5603/fm.2013.0017, indexed in Pubmed: 23740495.

10. Romani R, Elsharkawy A, Laakso A, et al. Tailored anterior clinoidectomy through the lateral supraorbital approach: experience with 82 consecutive patients. World Neurosurg. 2012; 77(3-4): 512-517, doi: 10.1016/j.wneu.2011.07.018, indexed in Pubmed: 22120327.

11. Froelich SC, Aziz KM, Levine NB, et al. Refinement of the extradural anterior clinoidectomy: surgical anatomy of the orbitotemporal periosteal fold. Neurosurgery. 2007; 61(5 Suppl 2): 179-85; discussion 185, doi: 10.1227/01. neu.0000303215.76477.cd, indexed in Pubmed: 18091231.

12. Iwasaki K, Toda H, Hashikata H, et al. Extradural Anterior Clinoidectomy and Optic Canal Unroofing for Paraclinoid and Basilar Aneurysms: Usefulness of a No-Drill Instrumental Method. Acta Neurochir Suppl. 2018; 129: 39-42, doi: 10.1007/978-3-319-73739-3_6, indexed in Pubmed: 30171312.

13. Andaluz N, Beretta F, Bernucci C, et al. Evidence for the improved exposure of the ophthalmic segment of the internal carotid artery after anterior clinoidectomy: morphometric analysis. Acta Neurochir (Wien). 2006; 148(9): 971-5; discussion 975, doi: 10.1007/s00701 006-0862-x, indexed in Pubmed: 16917665.

14. Ota N, Tanikawa R, Miyazaki T, et al. Surgical microanatomy of the anterior clinoid process for paraclinoid aneurysm surgery and efficient modification of extradural anterior clinoidectomy. World Neurosurg. 2015; 83(4): 635643, doi: 10.1016/j.wneu.2014.12.014, indexed in Pubmed: 25527880.

15. Hayashi N, Masuoka T, Tomita T, et al. Surgical anatomy and efficient modification of procedures for selective extradural anterior clinoidectomy. Minim Invasive Neurosurg. 2004; 47(6): 355-358, doi: 10.1055/s-2004-830121, indexed in Pubmed: 15674753.

16. Takahashi JA, Kawarazaki A, Hashimoto N. Intradural en-bloc removal of the anterior clinoid process. Acta Neurochir (Wien). 2004; 146(5): 505509, doi: 10.1007/s00701-004-0249-9, indexed in Pubmed: 15118888.

17. Seifert V, Güresir E, Vatter H. Exclusively intradural exposure and clip reconstruction in complex paraclinoid aneurysms. Acta Neurochir (Wien). 2011; 153(11): 2103-2109, doi: 10.1007/s00701-011-11716, indexed in Pubmed: 21953478.

18. Kikuta KI, Kitai R, Kodera T, et al. Predictive Factors for the Occurrence of Visual and Ischemic Complications After Open Surgery for Paraclinoid Aneurysms of the Internal Carotid Artery. Acta Neurochir Suppl. 2016; 123: 41-49, doi: 10.1007/978-3-319-29887-0_6, indexed in Pubmed: 27637627.

19. Romani R, Elsharkawy A, Laakso A, et al. Complications of anterior clinoidectomy through lateral supraorbital approach. World Neurosurg. 2012; 77(5-6): 698-703, doi: 10.1016/j.wneu.2011.08.014, indexed in Pubmed: 22120307.

20. Kshettry VR, Jiang X, Chotai S, et al. Optic nerve surface temperature during intradural anterior clinoidectomy: a comparison between high-speed diamond burr and ultrasonic bone curette. Neurosurg Rev. 2014; 37(3): 453-8; discussion 458, doi: 10.1007/s10143-0140547-5, indexed in Pubmed: 24801719.

21. Barnett SL, Whittemore B, Thomas J, et al. Intradural clinoidectomy and postoperative headache in patients undergoing aneurysm surgery. Neurosurgery. 2010; 67(4): 906-9; discussion 910, doi: 10.1227/ NEU.0b013e3181ec0f41, indexed in Pubmed: 20881554.

22. Tripathi M, Deo RC, Damodaran N, et al. Quantitative analysis of variable extent of anterior clinoidectomy with intradural and extradural approaches: 3-dimensional analysis and cadaver dissection. Neurosurgery. 2015; 11 Suppl 2: 147-60; discussion 160, doi: 10.1227/ NEU.0000000000000599, indexed in Pubmed: 25584957. 
23. Ochiai C, Wakai S, Inou S, et al. Preoperative angiographical prediction of the necessity to removal of the anterior clinoid process in internal carotid-posterior communicating artery aneurysm surgery. Acta Neurochir (Wien). 1989; 99(3-4): 117-121, doi: 10.1007/bf01402319, indexed in Pubmed: 2773681.

24. Kamide T, Burkhardt JK, Tabani H, et al. Preoperative Prediction of the Necessity for Anterior Clinoidectomy During Microsurgical Clipping of Ruptured Posterior Communicating Artery Aneurysms. World Neurosurg. 2018; 109: e493-e501, doi: 10.1016/j.wneu.2017.10.007, indexed in Pubmed: 29032217.

25. Park SK, Shin YS, Lim YC, et al. Preoperative predictive value of the necessity for anterior clinoidectomy in posterior communicating artery aneurysm clipping. Neurosurgery. 2009; 65(2): 281-5; discussion 285, doi: 10.1227/01.NEU.0000348296.09722.2F, indexed in Pubmed: 19625906.

26. Lee HW, Park HS, Yoo KS, et al. Measurement of Critical Structures around Paraclinoidal Area : A Cadaveric Morphometric Study. J Korean Neurosurg Soc. 2013; 54(1): 14-18, doi: 10.3340/jkns.2013.54.1.14, indexed in Pubmed: 24044074.

27. Batjer HH, Welch BG. Respecting the Clinoid: An Application of Preoperative Computed Tomography Angiography. World Neurosurg. 2015; 83(6): 1022-1023, doi: 10.1016/j.wneu.2015.01.032, indexed in Pubmed: 25659806.

28. Bouthillier A, Loveren Hv, Keller J. Segments of the Internal Carotid Artery: A New Classification. Neurosurgery. 1996; 38(3): 425-433, doi: 10.1227/00006123-199603000-00001.

29. Pechlivanis I, Schmieder K, Scholz M, et al. 3-Dimensional computed tomographic angiography for use of surgery planning in patients with intracranial aneurysms. Acta Neurochir (Wien). 2005; 147(10): 104553; discussion 1053, doi: 10.1007/s00701-005-0577-4, indexed in Pubmed: 16047107.

30. Kawashima M, Matsushima T, Miyazono M, et al. Two surgical cases of internal carotid-ophthalmic artery aneurysms: special reference to the usefulness of three-dimensional CT angiography. Neurol Res. 2002; 24(8): 825-828, doi: 10.1179/016164102101200807, indexed in Pubmed: 12500708.
31. Motoyama Y, Hironaka Y, Nishimura F, et al. Quantitative analysis of the trajectory of simulated basilar apex aneurysms through the internal carotid artery to assess the need for an orbitozygomatic approach. Acta Neurochir (Wien). 2017; 159(1): 85-92, doi: 10.1007/s00701016-3018-7, indexed in Pubmed: 27848082.

32. da Costa MD, de Oliveira Santos BF, de Araujo Paz D, et al. Anatomical Variations of the Anterior Clinoid Process: A Study of 597 Skull Base Computerized Tomography Scans. Oper Neurosurg (Hagerstown). 2016; 12(3): 289-297, doi: 10.1227/NEU.0000000000001138, indexed in Pubmed: 29506115.

33. Dolenc VV. A combined epi- and subdural direct approach to carotid-ophthalmic artery aneurysms. J Neurosurg. 1985; 62(5): 667-672, doi: 10.3171/jns.1985.62.5.0667, indexed in Pubmed: 3989589.

34. Vajkoczy P. Intradural versus extradural removal of the anterior clinoid process. World Neurosurg. 2012; 77(5-6): 615-616, doi: 10.1016/j. wneu.2011.10.026, indexed in Pubmed: 22120214.

35. Otani N, Muroi C, Yano H, et al. Surgical management of tuberculum sellae meningioma: role of selective extradural anterior clinoidectomy. Br J Neurosurg. 2006; 20(3): 129-138, doi: 10.1080/02688690600776747, indexed in Pubmed: 16801044.

36. Chang DJ. The "no-drill" technique of anterior clinoidectomy: a cranial base approach to the paraclinoid and parasellar region. Neurosurgery. 2009; 64(3 Suppl): ons96-105; discussion ons105, doi: 10.1227/01. NEU.0000335172.68267.01, indexed in Pubmed: 19240577.

37. Spektor S, Dotan S, Mizrahi CJ. Safety of drilling for clinoidectomy and optic canal unroofing in anterior skull base surgery. Acta Neurochir (Wien). 2013; 155(6): 1017-1024, doi: 10.1007/s00701-013-17042, indexed in Pubmed: 23605256.

38. Yonekawa Y, Ogata N, Imhof HG, et al. Selective extradural anterior clinoidectomy for supra- and parasellar processes. Technical note. J Neurosurg. 1997; 87(4): 636-642, doi: 10.3171/jns.1997.87.4.0636, indexed in Pubmed: 9322855.

39. Khan N, Yoshimura S, Roth P, et al. Conventional microsurgical treatment of paraclinoid aneurysms: state of the art with the use of the selective extradural anterior clinoidectomy SEAC. Acta Neurochir Suppl. 2005; 94: 23-29, doi: 10.1007/3-211-27911-3_5, indexed in Pubmed: 16060237. 